\title{
Combining quantitative and qualitative breast density measures to assess breast cancer risk
}

Karla Kerlikowske ${ }^{1,2,3^{*}}$, Lin Ma ${ }^{3}$, Christopher G. Scott ${ }^{4}$, Amir P. Mahmoudzadeh ${ }^{5}$, Matthew R. Jensen 4 , Brian L. Sprague ${ }^{6}$, Louise M. Henderson ${ }^{7}$, V. Shane Pankratz ${ }^{8}$, Steven R. Cummings ${ }^{9}$, Diana L. Miglioretti ${ }^{10,11}$, Celine M. Vachon ${ }^{4}$ and John A. Shepherd ${ }^{5}$

\begin{abstract}
Background: Accurately identifying women with dense breasts (Breast Imaging Reporting and Data System [BI-RADS] heterogeneously or extremely dense) who are at high breast cancer risk will facilitate discussions of supplemental imaging and primary prevention. We examined the independent contribution of dense breast volume and BI-RADS breast density to predict invasive breast cancer and whether dense breast volume combined with Breast Cancer Surveillance Consortium (BCSC) risk model factors (age, race/ethnicity, family history of breast cancer, history of breast biopsy, and BI-RADS breast density) improves identifying women with dense breasts at high breast cancer risk.
\end{abstract}

Methods: We conducted a case-control study of 1720 women with invasive cancer and 3686 control subjects. We calculated ORs and $95 \%$ Cls for the effect of BI-RADS breast density and Volpara ${ }^{\mathrm{TM}}$ automated dense breast volume on invasive cancer risk, adjusting for other BCSC risk model factors plus body mass index (BMI), and we compared C-statistics between models. We calculated BCSC 5-year breast cancer risk, incorporating the adjusted ORs associated with dense breast volume.

Results: Compared with women with BI-RADS scattered fibroglandular densities and second-quartile dense breast volume, women with BI-RADS extremely dense breasts and third- or fourth-quartile dense breast volume (75\% of women with extremely dense breasts) had high breast cancer risk (OR 2.87, 95\% Cl 1.84-4.47, and OR 2.56, 95\% Cl 1.87-3.52, respectively), whereas women with extremely dense breasts and first- or second-quartile dense breast volume were not at significantly increased breast cancer risk (OR 1.53, 95\% Cl 0.75-3.09, and OR 1.50, 95\% Cl 0.82-2. 73 , respectively). Adding continuous dense breast volume to a model with BCSC risk model factors and BMI increased discriminatory accuracy compared with a model with only BCSC risk model factors (C-statistic 0.639, 95\% $\mathrm{Cl} 0.623-0.654$, vs. C-statistic $0.614,95 \% \mathrm{Cl} 0.598-0.630$, respectively; $P<0.001)$. Women with dense breasts and fourth-quartile dense breast volume had a BCSC 5-year risk of 2.5\%, whereas women with dense breasts and firstquartile dense breast volume had a 5 -year risk $\leq 1.8 \%$.

Conclusions: Risk models with automated dense breast volume combined with BI-RADS breast density may better identify women with dense breasts at high breast cancer risk than risk models with either measure alone.

Keywords: Breast density, Breast cancer risk, Dense volume

\footnotetext{
* Correspondence: karla.kerlikowske@ucsf.edu

${ }^{1}$ Department of Epidemiology and Biostatistics, University of California, San

Francisco, CA, USA

${ }^{2}$ General Internal Medicine Section, San Francisco Veterans Affairs Medical

Center, 111A1, 4150 Clement Street, San Francisco, CA 94121, USA

Full list of author information is available at the end of the article
} 


\section{Background}

Many studies using both qualitative and quantitative breast density measures have found women with high breast density (greater amount of breast and connective tissue compared with fat) are at increased breast cancer risk [1]. The Breast Imaging Reporting and Data System (BI-RADS) breast density categories estimated subjectively by radiologists [2] is the standard for reporting breast density in clinical practice in the United States. Quantitative breast density measures are now available with commercial (Quantra ${ }^{\mathrm{TM}}$, Hologic, Inc., Marlborough, MA, USA; and Volpara ${ }^{\mathrm{TM}}$, Volpara Solutions/ Matakina Technology, Wellington, New Zealand) and publicly available (Laboratory for Individualized Breast Radiodensity Assessment [LIBRA]) software that can be used in clinical practice. Breast cancer associations appear to be similar with qualitative and quantitative measures examined [3-5].

BI-RADS breast density is estimated visually and reflects density quantity, distribution, and parenchymal pattern, whereas quantitative measures algorithmically assess absolute dense breast volume. The correlation of clinical BI-RADS density with quantitative dense breast volume (Quantra ${ }^{\mathrm{TM}}$, Volpara ${ }^{\mathrm{TM}}$ ) is modest [6-8]. Discordant associations between BI-RADS density and dense breast volume have been reported for black and Asian women. Asian women have a higher proportion of dense breasts (BI-RADS heterogeneously or extremely dense) than white women, but dense breast volume is lower in Asian women [4]. Conversely, black and white women have a similar proportion with dense breasts, but dense breast volume is higher in black than in white women [8]. This suggests clinical BI-RADS density and quantitative density measures may be measuring different aspects of breast density and possibly breast cancer risk.

About $50 \%$ of women with dense breasts are at low to average breast cancer risk (5-year risk $\leq 1.67 \%$ ) [9]. Accurately identifying women with dense breasts who are at high breast cancer risk (5-year risk $\geq 2.5 \%$ ) will facilitate discussions of supplemental imaging and primary prevention. Combining a qualitative or quantitative breast density measure with clinical risk factors estimates a woman's breast cancer risk more accurately than does either measure alone [3, 10-12]. No breast cancer risk prediction models have combined clinical risk factors and qualitative and quantitative measures of breast density. An advantage of incorporating dense breast volume into risk prediction models is that it is independent of clinical risk factors and only weakly confounded by body mass index (BMI) [4].

We evaluated the independent contribution and improved discriminatory accuracy of adding dense breast volume to the Breast Cancer Surveillance Consortium (BCSC) risk prediction model [3], which includes age, race/ethnicity, first-degree family history of breast cancer, history of breast biopsy, and BI-RADS breast density with additional adjustment for BMI to identify women with dense breasts who are at high breast cancer risk.

\section{Methods}

Study sample

Study participants were in one of three case-control studies nested within large prospective breast imaging cohorts. The San Francisco Mammography Registry (SFMR) and Vermont Breast Cancer Surveillance System (VBCSS) participate in the National Cancer Institutefunded BCSC (http://www.bcsc-research.org/) [13]. Both registries obtain annual institutional review board approval and passive permission for data collection and enrollment of participants, as well as data linkages for research purposes, and both received a Federal Certificate of Confidentiality that protects the identities of research participants. For the Mayo Clinic screening cohort, a waiver of informed consent and Health Insurance Portability and Accountability Act authorization from the participants was approved by the institutional review board. Only individuals who had not refused permission to use their medical records for research (according to Minnesota Research Authorization Statute) were included from the Mayo Clinic cohort [14].

The SFMR obtained "for processing" digital screening examinations done with Selenia machines (Hologic Inc.) at four facilities since 2006, and the VBCSS obtained them from one facility for screenings done since 2007, which serve as the underlying screening mammography cohort for each registry. Incident invasive breast cancers reported to the California Cancer Registry $(n=1052)$ or the Vermont Cancer Registry and pathology databases $(n=288)$ from January 2007 through November 2012 with a raw digital screening examination at least 6 months prior to diagnosis with no upper time limit were included. Two control subjects $(n=2678)$ without prior breast cancer were matched to each case on age within 5 years, race, date of screening examination within 1 year, mammography machine, and facility. The Mayo Clinic cohort obtained "for processing" digital images from Selenia machines from April 2008 through December 2013 from women in the tristate region of Minnesota, Iowa, and Wisconsin. Incident invasive breast cancers from this region reported to the Mayo Clinic tumor registry through December $2013(n=380)$ were included. Approximately three control subjects $(n=1008)$ without prior breast cancer were matched to each case on age within 5 years, race, state of residence, date of screening examination within 1 year, and mammography machine. We ensured that each control subject had at least one normal screening mammogram on or after the corresponding case's diagnosis date. Our total sample consisted of 1720 invasive cases and 3686 control subjects. 


\section{Measurement of risk factors}

Information on age, first-degree family history of breast cancer, race/ethnicity, prior breast biopsy history, height, weight, and age at first live birth were obtained from self-report (SFMR and VBCSS) at the time of mammography and from self-report or medical record review (height and weight) for the Mayo Clinic cohort. BMI was calculated by dividing weight in kilograms by height in square meters. Race/ethnicity was coded using the expanded definition currently used in the Surveillance, Epidemiology, and End Results program and U.S. vital statistics (non-Hispanic White, non-Hispanic black, Asian/Pacific Islander, Native American/Alaskan Native, Hispanic, other/mixed race). Age at first live birth was dichotomized as nulliparous or age $\geq 30$ years for first live birth compared with age at first birth $<30$ years.

\section{BI-RADS breast density and dense breast volume}

Practicing radiologists classified breast density as part of routine clinical practice at the time of mammography interpretation using the BI-RADS ${ }^{\oplus}$ density categories [2]: a $=$ almost entirely fat, $\mathrm{b}=$ scattered fibroglandular densities, $\mathrm{c}=$ heterogeneously dense, and $\mathrm{d}=$ extremely dense. Volpara $^{\mathrm{Tm}}$ version 1.5.0, which is the most common automated $3 \mathrm{D}$ density measurement tool used in clinical practice and research settings, is a fully automated method for assessing volumetric breast density that uses the measured breast thickness and X-ray attenuations in the "for processing" image to create estimates of dense and nondense tissue volume for each pixel. Summing the dense pixel volumes provides total dense breast volume. Volpara uses proprietary algorithms to calculate breast thickness and determine dense tissue volume [15] by averaging measures of each breast. For this study, we used the dense breast volume output from the vendor-specific software per woman, incorporating all four views (craniocaudal and mediolateral oblique of both breasts) of raw digital images as done in the clinical setting.

\section{Statistical methods}

We compared frequency distributions of demographics and risk factors between cases and control subjects. Dense breast volume quartiles were defined using control subjects from all sites. Within each BI-RADS category, the proportion of cases and control subjects within each dense breast volume quartile was calculated. Spearman's correlation coefficient was calculated to assess the association of BI-RADS density categories with continuous dense breast volume.

Conditional logistic regression stratified on matched set was used to examine the effects of BI-RADS density and dense breast volume on invasive breast cancer risk. Associations were summarized with ORs and 95\% CIs, and with AUROC or C-statistics, which accounted for the matched study design. Differences in C-statistics between models were tested using the SEs estimated from 5000 bootstrap samples. Models were adjusted for age, race/ethnicity, first-degree family history of breast cancer, history of benign breast biopsy, and BMI (continuous). We used the second BI-RADS category as a reference to allow for estimations of risk at the lowest and highest categories and because it is the most prevalent category. Study heterogeneity was evaluated by including an interaction term between study site and breast density measurement. Initially, we fit a model evaluating the association among all possible combinations of BI-RADS density and quartiles of dense breast volume in reference to women with scattered fibroglandular density and second-quartile dense breast volume. Differences in breast cancer association among combinations of BI-RADS density and quartiles of dense breast volume were evaluated by including a multiplicative interaction term. Then, separate models were evaluated that included BCSC clinical risk factors, with and without BMI, plus one or more measure(s) of breast density: BI-RADS density, continuous dense breast volume, and BI-RADS density plus continuous dense breast volume. Continuous dense breast volume was log-transformed and divided by its SD.

To examine the absolute risk associated with quartiles of dense breast volume, we incorporated the adjusted ORs associated with dense breast volume into the BCSC model. ORs for each quartile from the fully adjusted model were standardized for attributable fraction so that they measured increased or decreased risk relative to average risk. We calculated the estimated 5-year absolute risk from both the original model and the updated model for each subject and summarized these absolute risks across BI-RADS and dense breast volume categories. For those with heterogeneously or extremely dense breasts, the proportion of control subjects with risks $\geq 2.5 \%$ were calculated for each model. These proportions were then used to calculate the net gain in reclassification for the updated risk model including dense breast volume.

Analyses were performed using SAS version 9.4 software (SAS Institute, Cary, NC, USA). Two-sided statistical tests were used, and $P$ values $<0.05$ were considered to be statistically significant.

\section{Results}

We compared 1720 women with invasive breast cancer with 3686 matched women without breast cancer with breast density measured, on average, 2.4 years (range 6 months to 6 years) before cancer diagnosis. Women with invasive cancer were more likely to be nulliparous or $\geq 30$ years of age at first live birth, to have a family history of breast cancer, to have heterogeneously or extremely dense breasts, and to have higher mean dense 
breast volume (Table 1). A wide distribution of dense breast volume was observed within each BI-RADS density category (Table 2). Surprisingly, about one-third (30.5\%) of control subjects with almost entirely fat breasts had first-quartile dense breast volume $(\leq 35.9 \mathrm{ml})$, and about half $(54.1 \%)$ with extremely dense breasts had fourth-quartile $(>70.0 \mathrm{ml})$ dense breast volume. The correlation coefficient between continuous dense breast volume and BI-RADS density was $r=0.38$ (95\% CI 0.34-0.42) for cases and $r=0.31$ (95\% CI 0.29$0.34)$ for control subjects.

Quartiles of dense breast volume and BI-RADS density associations with breast cancer risk

In multivariable models that included clinical risk factors in the BCSC risk model with additional adjustment for BMI, compared with women with BI-RADS scattered fibroglandular density and second-quartile dense breast volume, women with BI-RADS extremely dense breasts and third or fourth-quartile dense breast volume (75\% of women with extremely dense breasts) had high breast cancer risk (OR 2.87, 95\% CI 1.84-4.47, and OR 2.56, 95\% CI 1.87-3.52, respectively), whereas women with extremely dense breasts and first- or second-quartile dense breast volume were not at significantly increased breast cancer risk (OR 1.53, 95\% CI 0.75-3.09, and OR 1.50, 95\% CI 0.82-2.73, respectively) (Table 3). Women with BI-RADS almost entirely fat breasts and first- or second-quartile dense breast volume $(63 \%$ of women with fatty breasts) had the lowest breast cancer risk (OR 0.63, 95\% CI 0.45-0.89, and OR 0.60, 95\% CI $0.43-$ 0.84 , respectively). There was no significant interaction between BI-RADS density and dense breast volume associations with breast cancer $(P=0.75)$.

\section{Continuous dense breast volume and BI-RADS density and breast cancer risk associations}

In multivariable models that included risk factors in the BCSC risk model with additional adjustment for BMI,

Table 1 Characteristics of study sample

\begin{tabular}{|c|c|c|}
\hline & Invasive breast cancer cases $(n=1720)$ & Matched control subjects $(n=3686)$ \\
\hline Age, years, mean (SD) & $59.5(12.1)$ & $59.6(12.0)$ \\
\hline Body mass index, $\mathrm{kg} / \mathrm{m}^{2}$, mean (SD) & $26.3(5.7)$ & $26.2(5.7)$ \\
\hline Dense breast volume, ${ }^{a} \mathrm{ml}$, median (IQR) & $57.8(41.0-82.5)$ & $50.7(36.8-70.2)$ \\
\hline \multicolumn{3}{|l|}{ Age at first live birth, $n(\%)$} \\
\hline$<30$ years & $856(50.1 \%)$ & 2085 (56.6\%) \\
\hline None or $\geq 30$ years & $852(49.9 \%)$ & 1600 (43.4\%) \\
\hline \multicolumn{3}{|l|}{ Family history of breast cancer, ${ }^{\mathrm{b}} \mathrm{n}(\%)$} \\
\hline No & $1218(71.2 \%)$ & $2991(81.2 \%)$ \\
\hline Yes & $493(28.8 \%)$ & $693(18.8 \%)$ \\
\hline \multicolumn{3}{|l|}{ History of breast biopsy, $n$ (\%) } \\
\hline No & $1304(76.4 \%)$ & 3040 (82.6\%) \\
\hline Yes & $402(23.6 \%)$ & $641(17.4 \%)$ \\
\hline \multicolumn{3}{|l|}{ Race/ethnicity, n (\%) } \\
\hline White & $1380(80.3 \%)$ & 3012 (81.7\%) \\
\hline Asian & $218(12.7 \%)$ & $437(11.9 \%)$ \\
\hline Black & $34(2.0 \%)$ & $67(1.8 \%)$ \\
\hline Hispanic & $37(2.2 \%)$ & $101(2.7 \%)$ \\
\hline Other & $50(2.9 \%)$ & $69(1.9 \%)$ \\
\hline \multicolumn{3}{|l|}{ BI-RADS breast density, $n(\%)$} \\
\hline Almost entirely fat (a) & $233(13.5 \%)$ & $731(19.8 \%)$ \\
\hline Scattered fibroglandular densities (b) & $668(38.8 \%)$ & $1557(42.2 \%)$ \\
\hline Heterogeneously dense (c) & $600(34.9 \%)$ & $1115(30.2 \%)$ \\
\hline Extremely dense (d) & 219 (12.7\%) & $283(7.7 \%)$ \\
\hline
\end{tabular}

BI-RADS Breast Imaging Reporting and Data System

Data are presented as number (percent) missing for cases and control subjects for age at first birth (13 [0.2\%]), family history of breast cancer (11 [0.2\%]), history of breast biopsy (19 [0.4\%]), and race/ethnicity (3 [0.1\%])

${ }^{a}$ Measured with Volpara software

${ }^{b}$ Mother, sister, or daughter with breast cancer

'BI-RADS breast density: $a=$ almost entirely fat, $b=$ scattered fibroglandular densities, $c=$ heterogeneously dense, $d=$ extremely dense 
Table 2 Frequency distribution of volumetric density within Breast Imaging Reporting and Data System breast density categories

\begin{tabular}{|c|c|c|c|c|c|c|c|c|}
\hline \multirow{3}{*}{$\begin{array}{l}\text { Dense breast } \\
\text { volume, }{ }^{b} \mathrm{ml}\end{array}$} & \multicolumn{4}{|c|}{ Control subjects } & \multicolumn{4}{|l|}{ Cases } \\
\hline & \multicolumn{4}{|c|}{ BI-RADS breast density ${ }^{a}$} & \multicolumn{4}{|c|}{ BI-RADS breast density ${ }^{a}$} \\
\hline & $\begin{array}{l}a \\
n=731 \\
\%\end{array}$ & $\begin{array}{l}b \\
n=1557 \\
\%\end{array}$ & $\begin{array}{l}c \\
n=1115 \\
\%\end{array}$ & $\begin{array}{l}d \\
n=283 \\
\%\end{array}$ & $\begin{array}{l}a \\
n=233 \\
\%\end{array}$ & $\begin{array}{l}b \\
n=668 \\
\%\end{array}$ & $\begin{array}{l}c \\
n=600 \\
\%\end{array}$ & $\begin{array}{l}d \\
n=219 \\
\%\end{array}$ \\
\hline Quartile 1: $\leq 35.9$ & 30.5 & 28.0 & 15.2 & 9.9 & 26.2 & 24.4 & 9.7 & 5.9 \\
\hline Quartile 2: 36.0-50.0 & 32.1 & 28.5 & 19.3 & 15.2 & 30.0 & 27.7 & 17.3 & 9.1 \\
\hline Quartile 3: 50.1-70.0 & 27.5 & 26.3 & 26.3 & 20.8 & 29.6 & 26.9 & 25.7 & 23.7 \\
\hline Quartile 4: 70.1+ & 9.8 & 17.2 & 39.3 & 54.1 & 14.2 & 21.0 & 47.3 & 61.2 \\
\hline
\end{tabular}

BI-RADS Breast Imaging Reporting and Data System

${ }^{a}$ BI-RADS breast density: $a=$ almost entirely fat, $b=$ scattered fibroglandular densities, $c=$ heterogeneously dense, $d=$ extremely dense

${ }^{\mathrm{b}}$ Measured with Volpara software

women with BI-RADS extremely dense breasts were at 2.45 times higher risk than women with scattered fibroglandular densities (Table 4). In a separate model, continuous dense breast volume increased risk $33 \%$ per 1SD increase in dense breast volume. When combining continuous dense breast volume and BI-RADS density in the same multivariable model, associations with breast cancer were attenuated, but both density variables remained statistically significant (Table 4). There was no evidence of study heterogeneity for models with BIRADS density or dense breast volume assessed by quartile or continuously $(P=0.95, P=0.71$, and $P=0.41$, respectively).

\section{Model discrimination}

Adding continuous dense breast volume to a model with BCSC risk model factors showed improved discrimination of case status (C-statistic 0.627, 95\% CI 0.6110.642 , vs. C-statistic $0.614,95 \%$ CI $0.598-0.630$, respectively; $P=0.02$ ) (Table 4). Adding continuous dense breast volume to a model with BCSC risk model factors and BMI further increased discriminatory accuracy compared with a model with only BCSC risk model factors (C-statistic $0.639,95 \%$ CI $0.623-0.654$, vs. C-statistic $0.614,95 \%$ CI $0.598-0.630$, respectively; $P<0.001$ ). Adding quartiles of dense breast volume to a model with
BCSC risk model factors and BMI had less discrimination than a model with continuous dense breast volume (C-statistic 0.629, 95\% CI 0.614-0.645) (model results not shown).

\section{Absolute breast cancer risk combining BI-RADS density and dense breast volume}

The mean 5-year breast cancer risk for women with BIRADS heterogeneously or extremely dense breasts is $2.0 \%$. The 5-year risk is higher when considering BIRADS density and dense breast volume (Table 5). For example, women with BI-RADS heterogeneously or extremely dense breasts and fourth-quartile dense breast volume had a 5 -year risk of $2.5 \%$. Overall, the proportion of women with heterogeneously or extremely dense breasts with 5 -year risk $\geq 2.5 \%$ increased from $20.3 \%$ to $30.5 \%$ when combined with a dense breast volume measure. The proportion of cancers with heterogeneously dense breasts and 5-year risk of $\geq 2.5 \%$ increased from $24.3 \%$ to $37.9 \%$ when taking into account a continuous dense breast volume measure, whereas control subjects increased from $19.2 \%$ to $29.8 \%$, for a net gain of $3.2 \%$ of high-risk women identified as having cancer. For women with extremely dense breasts, the proportion of breast cancers increased from $29.2 \%$ to $43.1 \%$ when taking into account a continuous dense breast volume measure, and

Table 3 Breast cancer risk associated with Breast Imaging Reporting and Data System breast density cross-classified with dense breast volume

\begin{tabular}{|c|c|c|c|c|c|}
\hline \multirow{2}{*}{$\begin{array}{l}\text { Dense breast } \\
\text { volume, }{ }^{b} \mathrm{ml}\end{array}$} & BI-RADS breast density $a^{a}$ & BI-RADS breast density $b^{a}$ & BI-RADS breast density $c^{a}$ & BI-RADS breast density $d^{a}$ & Overall \\
\hline & OR $(95 \% \mathrm{Cl})^{c}$ & OR $(95 \% \mathrm{Cl})^{c}$ & OR $(95 \% \mathrm{Cl})^{c}$ & OR $(95 \% \mathrm{Cl})^{c}$ & OR $(95 \% \mathrm{Cl})^{\mathrm{C}}$ \\
\hline Quartile 1: $\leq 35.9$ & $\mathbf{0 . 6 3}(0.45-0.89)$ & $0.94(0.72-1.21)$ & $1.03(0.71-1.49)$ & $1.53(0.75-3.09)$ & $0.85(0.71-1.03)$ \\
\hline Quartile 2: 36.0-50.0 & $\mathbf{0 . 6 0}(0.43-0.84)$ & 1.00 (reference) & $1.25(0.92-1.69)$ & $1.50(0.82-2.73)$ & 1.00 (reference) \\
\hline Quartile 3: 50.1-70.0 & $\mathbf{0 . 7 0}(0.49-0.99)$ & $0.98(0.76-1.27)$ & $1.43(1.09-1.89)$ & $2.87(1.84-4.47)$ & $1.19(1.00-1.42)$ \\
\hline Quartile 4: 70.1+ & $0.87(0.54-1.41)$ & $1.15(0.87-1.53)$ & $1.67(1.31-2.12)$ & $2.56(1.87-3.52)$ & $1.62(1.36-1.92)$ \\
\hline
\end{tabular}

BI-RADS Breast Imaging Reporting and Data System

${ }^{a}$ BI-RADS breast density: $a=$ almost entirely fat, $b=$ scattered fibroglandular densities, $c=$ heterogeneously dense, $d=$ extremely dense

${ }^{\mathrm{b}}$ Measured with Volpara software

'Adjusted for age, body mass index, family history of breast cancer, history of breast biopsy, and race/ethnicity. Statistically significant results are shown in boldface type 
Table 4 Multivariable models with Breast Imaging Reporting and Data System breast density, dense breast volume, or both, with and without adjustment for body mass index

\begin{tabular}{|c|c|c|c|c|c|c|}
\hline & $\begin{array}{l}\text { BI-RADS } \\
\text { breast density }\end{array}$ & $\begin{array}{l}\text { Continuous dense } \\
\text { breast volume }\end{array}$ & $\begin{array}{l}\text { BI-RADS breast density } \\
+ \text { continuous dense } \\
\text { breast volume }\end{array}$ & $\begin{array}{l}\text { BI-RADS } \\
\text { breast density } \\
\text { adjusted for BMI }\end{array}$ & $\begin{array}{l}\text { Continuous dense } \\
\text { breast volume adjusted } \\
\text { for BMI }\end{array}$ & $\begin{array}{l}\text { BI-RADS breast density } \\
+ \text { continuous dense } \\
\text { breast volume adjusted } \\
\text { for BMl }\end{array}$ \\
\hline & $\begin{array}{l}\mathrm{OR}^{\mathrm{a}} \\
(95 \% \mathrm{Cl})\end{array}$ & $\begin{array}{l}\mathrm{OR}^{\mathrm{a}} \\
(95 \% \mathrm{Cl})\end{array}$ & $\begin{array}{l}\mathrm{OR}^{\mathrm{a}} \\
(95 \% \mathrm{Cl})\end{array}$ & $\begin{array}{l}\mathrm{OR}^{\mathrm{b}} \\
(95 \% \mathrm{Cl})\end{array}$ & $\begin{array}{l}\mathrm{OR}^{\mathrm{b}} \\
(95 \% \mathrm{Cl})\end{array}$ & $\begin{array}{l}\mathrm{OR}^{\mathrm{b}} \\
(95 \% \mathrm{Cl})\end{array}$ \\
\hline \multicolumn{7}{|c|}{ BI-RADS breast density } \\
\hline $\begin{array}{l}\text { Almost entirely } \\
\text { fat }=a\end{array}$ & $\mathbf{0 . 7 4}(0.62-0.89)$ & & $\mathbf{0 . 7 7}(0.64-0.92)$ & $\mathbf{0 . 6 5}(0.54-0.78)$ & & $\mathbf{0 . 6 9}(0.57-0.84)$ \\
\hline $\begin{array}{l}\text { Scattered } \\
\text { fibroglandular } \\
\text { densities }=b\end{array}$ & 1.00 (reference) & & 1.00 (reference) & 1.00 (reference) & & 1.00 (reference) \\
\hline $\begin{array}{l}\text { Heterogeneously } \\
\text { dense }=c\end{array}$ & $1.34(1.16-1.55)$ & & $1.17(1.01-1.36)$ & $1.45(1.25-1.68)$ & & $1.26(1.07-1.48)$ \\
\hline $\begin{array}{l}\text { Extremely } \\
\text { dense }=\mathrm{d}\end{array}$ & $2.01(1.61-2.51)$ & & $1.63(1.30-2.05)$ & $2.45(1.93-3.09)$ & & $1.93(1.50-2.48)$ \\
\hline $\begin{array}{l}\text { Dense breast } \\
\text { volume, ml, } \\
\text { per } \mathrm{SD}^{\mathrm{C}}\end{array}$ & & $1.34(1.26-1.42)$ & $1.26(1.18-1.35)$ & & $1.33(1.25-1.42)$ & $1.20(1.11-1.29)$ \\
\hline C-statistic $^{d}$ & $0.614(0.598-0.630)$ & $0.623(0.607-0.639)$ & $0.627(0.611-0.642)$ & $0.634(0.618-0.649)$ & $0.630(0.614-0.645)$ & $0.639(0.623-0.654)$ \\
\hline
\end{tabular}

BI-RADS Breast Imaging Reporting and Data System, BMI Body mass index

${ }^{a}$ Adjusted for age, race/ethnicity, history of breast biopsy, family history of breast cancer. Statistically significant results are shown in boldface type

${ }^{\mathrm{b}}$ Adjusted for age, race/ethnicity, history of breast biopsy, family history of breast cancer, BMI. Statistically significant results are shown in boldface type

${ }^{\mathrm{C}}$ Measured with Volpara software, log-transformed

${ }^{\mathrm{d}} \mathrm{C}$-statistic represents the AUROC

that of control subjects increased from $24.8 \%$ to $34.0 \%$, for a net gain of $4.7 \%$ of high-risk women identified as having cancer. Dense breast volume did not change the predicted risk significantly for women with BI-RADS almost entirely fat or scattered fibroglandular breast density.

\section{Discussion}

We found that adding a continuous measure of dense breast volume to risk prediction models which include BI-RADS breast density and clinical risk factors improves discriminatory accuracy, in particular for women with heterogeneously or extremely dense breasts. Among women aged $40-74$ years, an estimated $43.3 \%$ of women have dense breasts [16], but not all women with dense breasts are at increased risk of breast cancer [9]. Adding a volumetric breast density measure may improve discrimination of women with dense breasts who are considering supplemental screening or primary prevention, given the wide variation in BI-RADS density assessment across radiologists [17].

There are no evidence-based consensus guidelines for screening women with dense breasts. A 2013 Cochrane review and the evidence review for the 2015 U.S Preventive Services Task Force recommendations concluded that no data currently exist to provide evidence for or against the use of supplemental screening ultrasonography in

Table 5 Breast Cancer Surveillance Consortium 5-year breast cancer risk by Breast Imaging Reporting and Data System breast density with the addition of dense breast volume

\begin{tabular}{|c|c|c|c|c|}
\hline & BI-RADS breast density $\mathrm{a}^{\mathrm{a}}$ & BI-RADS breast density $b^{a}$ & BI-RADS breast density $c^{a}$ & BI-RADS breast density $d^{a}$ \\
\hline & 5-year risk, mean (SD) & 5-year risk, mean (SD) & 5-year risk, mean (SD) & 5-year risk, mean (SD) \\
\hline \multicolumn{5}{|l|}{ Dense breast volume, ${ }^{\mathrm{b}} \mathrm{ml}$} \\
\hline Quartile 1: $\leq 35.9$ & $0.9(0.5)$ & $1.6(0.9)$ & $1.8(1.1)$ & $1.5(0.8)$ \\
\hline Quartile 2: 36.0-50.0 & $1.1(0.6)$ & $1.7(0.9)$ & $2.1(1.3)$ & $2.3(1.7)$ \\
\hline Quartile 3: 50.1-70.0 & $1.0(0.7)$ & $1.8(1.1)$ & $2.2(1.3)$ & $2.4(1.6)$ \\
\hline Quartile 4: 70.1+ & $1.2(0.7)$ & $1.9(1.2)$ & $2.5(1.5)$ & $2.5(1.6)$ \\
\hline Mean BCSC 5-year risk & $1.0(0.6)$ & $1.7(1.0)$ & $2.0(1.2)$ & $2.0(1.4)$ \\
\hline
\end{tabular}

BCSC Breast Cancer Surveillance Consortium, BI-RADS Breast Imaging Reporting and Data System

${ }^{a}$ BI-RADS breast density: $a=$ almost entirely fat, $b=$ scattered fibroglandular densities, $c=$ heterogeneously dense, $d=$ extremely dense

${ }^{\mathrm{b}}$ Measured with Volpara software 
women with dense breasts, and they challenged investigators to provide such evidence $[18,19]$. The 2010 guidelines of the Society of Breast Imaging and the American College of Radiology recommend that ultrasound be considered as supplemental screening for women at high risk and in women with dense breasts [20]. Fifty percent of women with dense breasts have low breast cancer risk ( $<1.67 \%$ 5-year risk) [9]. Thus, combinations of breast cancer risk factors and qualitative and quantitative measures of breast density could be used to better identify women with dense breasts at high breast cancer risk who may benefit from a more intense screening strategy.

The variability in the patterns and amounts of dense tissue portrayed on the mammogram has been characterized by qualitative measures. The Wolfe scale qualitatively assesses breast density by classifying images into one of four patterns (N1 [fatty], P1, P2 [areas of increasing ductal prominence], and DY [significant densities or dysplasia]) on the basis of quantity and distribution of breast density [21]. The BI-RADS density qualitative assessment is similar to the Wolfe scale in that it incorporates the quantity, distribution, and texture of breast density. New automated commercial technologies are available to quantify breast density volume using methods such as Volpara ${ }^{\mathrm{TM}}$ and Quantra ${ }^{\mathrm{TM}}$. Texture features or parenchymal complexity has been evaluated on film-screen mammography examinations and shown to be independent of percentage breast density and relative amounts of fibroglandular tissue [22, 23]. Winkel et al. [22] showed that the discriminatory accuracy was highest when a combination of three methods of assessing relative amounts of density and texture on filmscreen mammography examinations were combined. Automated evaluation of textural features or parenchymal complexity of breast density is under investigation for digital images, with researchers in several studies reporting features as independent predictors of breast cancer risk [24-26]. Our results extend the literature by showing that an automated quantitative breast density measure (dense breast volume) available in clinical practice combined with a qualitative measure that incorporates the quantity, distribution, and texture of breast density (BIRADS breast density) improves the classification of women with dense breasts at high breast cancer risk.

Among women with dense breasts, $24 \%$ are at high risk of an interval cancer ( $>1$ per 1000 screening examinations) and warrant discussions of supplemental imaging [9]. Interval cancer rates are highest among women with extremely or heterogeneously dense breasts and BCSC 5-year breast cancer risk of $2.5 \%$ or higher (21\% of women with dense breasts) [9]. If continuous dense breast volume was assessed in combination with BCSC risk, $30.5 \%$ of women with dense breasts would have a 5 -year risk of $2.5 \%$ or higher and qualify for discussions of supplemental imaging or hormone therapy for primary prevention [27]. Moreover, continuous dense breast volume assessed in combination with BCSC model risk factors increases the identification of women with dense breasts at high breast cancer risk to a greater extent than measuring single-nucleotide polymorphisms [28]. Future studies should confirm whether interval cancer rates are higher among women with BI-RADS dense breasts and high dense breast volume than BI-RADS density alone.

This is the largest study to date involving an examination of the combination of an automated quantitative measure of dense breast volume and BI-RADS breast density on digital mammography examinations and their independent contribution to breast cancer risk. We examined Volpara's automated dense breast volume measure. Other commercially (Quantra ${ }^{\mathrm{TM}}$ ) and publicly (LIBRA) [29] available automated breast density software could be tested to verify our results. We used clinical BI-RADS density assessments when the definitions from the BI-RADS fourth edition were available in clinical practice. Studies using data collected since the release of the BI-RADS fifth edition, whose categories attempt to put more emphasis on the masking effect of dense tissue, should be assessed to ensure our results are robust. In studies for interrater and intrarater reliability of the BI-RADS categories, investigators have reported moderate to substantial agreement [30-32]. Thus, misclassification of BI-RADS categories may have influenced our results, such that some of the differences we observed could result in an under- or overestimation of associations [33]. Our population was predominantly white and Asian; studies should be repeated with black and Hispanic women to ensure generalizability of results across all racial/ethnic groups. Last, our study included women undergoing digital mammography, which is the primary modality used in the United States. Breast tomosynthesis is an emerging breast imaging modality that is being used for breast screening in $40 \%$ of certified U.S. facilities as of August 1, 2017 [34]; as such, the independent contribution of qualitative and quantitative density measures to breast cancer risk for this modality needs to be established.

\section{Conclusions}

We found that the combination of automated quantitative and qualitative clinical assessments of breast density can better identify women with dense breasts at high breast cancer risk than either measure alone. In future studies, researchers should assess automated dense breast volume measures in combination with automated parenchymal complexity features, as well as qualitative breast density measures, because both may measure different aspects of breast density than quantitative measures when assessing breast cancer risk and screening outcomes [35]. 


\section{Abbreviations}

BCSC: Breast Cancer Surveillance Consortium; BI-RADS: Breast Imaging Reporting and Data System; BMI: Body mass index; LIBRA: Laboratory for Individualized Breast Radiodensity Assessment; NCl: National Cancer Institute; SFMR: San Francisco Mammography Registry; VBCSS: Vermont Breast Cancer Surveillance System

\section{Acknowledgements}

The collection of cancer and vital status data used in this study was supported in part by several state public health departments and cancer registries throughout the United States. For a full description of these sources, please see http://www.bcsc-research.org/work/ acknowledgement.html. We thank the BCSC investigators, participating mammography facilities, and radiologists for the data they provided for this study. A list of the BCSC investigators and procedures for requesting BCSC data for research purposes are provided at http://www.bcsc-research.org/.

\section{Funding}

This work was supported by a National Institutes of Health, National Cancer Institute (NCl)-funded program project (P01 CA154292) and NCl grant R01 CA177150. Data collection was additionally supported by the Breast Cancer Surveillance Consortium (HHSN261201100031C); Vermont Breast Cancer Surveillance System data collection was also supported by $\mathrm{NCl}$ grant U54CA163303. The NCl had no role in the study's design; in the collection, analysis, and interpretation of the data; in the writing of the manuscript; or in the decision to submit the manuscript for publication.

\section{Availability of data and materials}

The datasets generated and/or analyzed during the present study are not publicly available, owing to an ongoing grant, but they are available from the corresponding author on reasonable request.

\section{Authors' contributions}

KK was responsible for study design, study conduct, and data collection; directed statistical analyses and data interpretation; drafted the manuscript; and revised and approved the final manuscript. LM performed statistical data analysis and data interpretation. CGS performed statistical data analysis and data interpretation, as well as revised and approved the final manuscript. APM acquired raw images and measured quantitative breast density. BLS was responsible for study conduct, data collection, and data interpretation, as well as revised and approved the final manuscript. MRJ performed statistical data analysis and data interpretation. LMH was responsible for study conduct, data collection, and data interpretation, as well as revised and approved the final manuscript. VSP performed statistical data analysis, directed statistical analyses and data interpretation, and revised and approved the final manuscript. SRC collected and interpreted data, as well as revised and approved the final manuscript. DLM was responsible for study design and statistical data analysis, directed statistical analyses and data interpretation, and revised and approved the final manuscript. CMV was responsible for study design, study conduct, and data collection; directed statistical analyses and data interpretation; and revised and approved the final manuscript. JAS acquired raw images, measured quantitative breast density, interpreted data, and revised and approved the final manuscript. All authors read and approved the final manuscript.

\section{Ethics approval and consent to participate}

The San Francisco Mammography Registry and Vermont Breast Cancer Surveillance System registries obtain annual institutional review board approval and passive permission for data collection and enrollment of participants, as well as data linkages for research purposes, and they received a Federal Certificate of Confidentiality that protects the identities of research participants. For the Mayo Clinic screening cohort, a waiver of informed consent and Health Insurance Portability and Accountability Act authorization from the participants was approved by the institutional review board. Only individuals who had not refused permission to use their medical records for research were included from the Mayo Clinic cohort.

\section{Consent for publication}

Not applicable.

\section{Competing interests}

The authors declare that they have no competing interests.

\section{Publisher's Note}

Springer Nature remains neutral with regard to jurisdictional claims in published maps and institutional affiliations.

\section{Author details}

${ }^{1}$ Department of Epidemiology and Biostatistics, University of California, San Francisco, CA, USA. ${ }^{2}$ General Internal Medicine Section, San Francisco Veterans Affairs Medical Center, 111A1, 4150 Clement Street, San Francisco, CA 94121, USA. ${ }^{3}$ Department of Medicine, University of California, San Francisco, CA, USA. ${ }^{4}$ Division of Biomedical Statistics and Informatics, Department of Health Sciences Research, Mayo Clinic College of Medicine, Rochester, MN, USA. ${ }^{5}$ Department of Radiology, University of California, San Francisco, CA, USA. 'Department of Surgery, University of Vermont, Burlington, VT, USA. ${ }^{7}$ Department of Radiology, School of Medicine, University of North Carolina, Chapel Hill, NC, USA. ${ }^{8}$ Department of Internal Medicine, University of New Mexico, Albuquerque, NM, USA. ${ }^{9}$ San Francisco Coordinating Center, California Pacific Medical Center Research Institute, San Francisco, CA, USA. ${ }^{10}$ Department of Public Health Sciences, University of California, Davis, CA, USA. ${ }^{11}$ Group Health Research Institute, Group Health Cooperative, Seattle, WA, USA.

Received: 6 February 2017 Accepted: 4 August 2017

Published online: 22 August 2017

\section{References}

1. McCormack V, Dos Santos S. Breast density and parenchymal patterns as markers of breast cancer risk: a meta-analysis. Cancer Epidemiol Biomarkers Prev. 2006;15(6):1159-69.

2. American College of Radiology. American College of Radiology Breast Imaging Reporting and Data System Atlas (BI-RADS ${ }^{\circledR}$ Atlas). Vol. 5. Reston: American College of Radiology; 2013.

3. Tice JA, Miglioretti DL, Li CS, Vachon CM, Gard CC, Kerlikowske K. Breast density and benign breast disease: risk assessment to identify women at high risk of breast cancer. J Clin Oncol. 2015;33(28):3137-43.

4. Brandt KR, Scott CG, Ma L, Mahmoudzadeh AP, Jensen MR, Whaley DH, Wu FF, Malkov S, Hruska CB, Norman AD, et al. Comparison of clinical and automated breast density measurements: implications for risk prediction and supplemental screening. Radiology. 2016;279(3):710-9.

5. Jeffers A, Sieh W, Lipson J, Rothstein JH, McGuire V, Whittemore AS, Rubin $\mathrm{DL}$. Breast cancer risk and mammographic density assessed with semiautomated and fully automated methods and BI-RADS. Radiology. 2017:282(2):348-55.

6. Lee H, Sohn Y, Han K. Comparison of mammographic density estimation by Volpara software with radiologists' visual assessment: analysis of clinicalradiologic factors affecting discrepancy between them. Acta Radiol. 2015; 56(9):1061-8.

7. Youk JH, Gweon HM, Son EJ, Kim JA. Automated volumetric breast density measurements in the era of the BI-RADS Fifth Edition: a comparison with visual assessment. Am J Roentgenol. 2016;206(5):1056-62.

8. McCarthy AM, Keller BM, Pantalone LM, Hsieh MK, Synnestvedt M, Conant EF, Armstrong K, Kontos D. Racial differences in quantitative measures of area and volumetric breast density. J Natl Cancer Inst. 2016;108(10):djw104.

9. Kerlikowske K, Zhu W, Tosteson AN, Spraque BL, Tice JA, Lehman CD, et al. Identifying women with dense breasts at high risk for interval cancer: a cohort study. Ann Intern Med. 2015:162(10):673-81.

10. Barlow W, White E, Ballard-Barbash R, Vacek PM, Titus-Ernstoff LT, Carney PA, Tice JA, Buist D, Geller BM, Rosenberg R, et al. A prospective breast cancer risk prediction model among women undergoing screening mammography. J Natl Cancer Inst. 2006;98(17):1204-14.

11. Chen J, Pee D, Ayyagari R, Graubard B, Schairer C, Byrne C, Benichou J, Gail $\mathrm{MH}$. Projecting absolute invasive breast cancer risk in white women with a model that includes mammographic density. J Natl Cancer Inst. 2006;98(17): 1215-26.

12. Tice JA, Cummings SR, Smith-Bindman R, Ichikawa L, Barlow WE, Kerlikowske K. Using clinical factors and mammographic breast density to estimate breast cancer risk: development and validation of a new predictive model. Ann Intern Med. 2008;148(5):337-47. 
13. Ballard-Barbash R, Taplin SH, Yankaskas BC, Ernster VL, Rosenberg RD, Carney PA, Barlow WE, Geller BM, Kerlikowske K, Edwards BK, et al. Breast Cancer Surveillance Consortium: a national mammography screening and outcomes database. AJR Am J Roetengol. 1997;169(4):1001-8.

14. St Sauver JL, Grossardt BR, Yawn BP, Melton LJ, Pankratz JJ, Brue SM, Rocca WA. Data resource profile: the Rochester Epidemiology Project (REP) medical records-linkage system. Int J Epidemiol. 2012;41(6):1614-24.

15. Volpara Solutions for Matakina Technology. Volpara Density ${ }^{\mathrm{TM}}$ user manual version 1.5.0. Wellington: Matakina Technology; 2013.

16. Sprague BL, Gangnon RE, Burt V, et al. Prevalence of mammographically dense breasts in the United States. J Natl Cancer Inst. 2014;106(10):dju255.

17. Sprague BL, Conant EF, Onega T, Garcia MP, Beaber EF, Herschorn SD, Lehman CD, Tosteson AN, Lacson R, Schnall MD, et al. Variation in mammographic breast density assessments among radiologists in clinical practice: a multicenter observational study. Ann Intern Med. 2016;165(7): 457-64

18. Gartlehner G, Flamm M. Is the Cochrane Collaboration prepared for the era of patient-centred outcomes research? Cochrane Database Syst Rev. 2013;3: ED000054.

19. Melnikow J, Fenton J, Whitlock E, Miglioretti DL, Weyrich MS, Thompson JH, Shah K. Adjunctive screening for breast cancer in women with dense breasts: a systematic review for the U.S. Preventive Services Task Force, AHRQ Publication No. 14-05201-EF-2. Agency for Healthcare Research and Quality: Rockville; 2015

20. Lee CH, Dershaw DD, Kopans D, Evans P, Monsees B, Monticciolo D, Brenner RJ, Bassett L, Berg W, Feig S, et al. Breast cancer screening with imaging: recommendations from the Society of Breast Imaging and the ACR on the use of mammography, breast MRI, breast ultrasound, and other technologies for the detection of clinically occult breast cancer. J Am Coll Radiol. 2010;7(1):18-27.

21. Wolfe JN. Risk for breast cancer development determined by mammographic parenchymal pattern. Cancer. 1976:37(5):2486-92.

22. Winkel RR, von Euler-Chelpin M, Nielsen M, Petersen $K$, Lillholm M, Nielsen MB, Lynge E, Uldall WY, Vejborg I. Mammographic density and structural features can individually and jointly contribute to breast cancer risk assessment in mammography screening: a case-control study. BMC Cancer. 2016;16:414

23. Malkov S, Shepherd JA, Scott CG, Tamimi RM, Ma L, Bertrand KA, Couch F, Jensen MR, Mahmoudzadeh AP, Fan B, et al. Mammographic texture and risk of breast cancer by tumor type and estrogen receptor status. Breast Cancer Res. 2016;18(1):122. A published erratum appears in Breast Cancer Res. 2017;19(1):1.

24. Gastounioti A, Conant E, Kontos D. Beyond breast density: a review on the advancing role of parenchymal texture analysis in breast cancer risk assessment. Breast Cancer Res. 2016;18(1):91.

25. Zheng Y, Keller B, Ray S, Wang Y, Conant EF, Gee JC, Kontos D. Parenchymal texture analysis in digital mammography: a fully-automated pipeline for breast cancer risk assessment. Med Phys. 2015;42(7):4149-60.

26. Sun W, Tseng TL, Qian W, Zhang J, Saltzstein EC, Zheng B, Lure F, Yu H, Zhou S. Using multiscale texture and density features for near-term breast cancer risk analysis. Med Phys. 2015;42(6):2853-62.

27. Moyer VA, U.S. Preventive Services Task Force. Medications to decrease the risk for breast cancer in women: recommendations from the U.S. Preventive Services Task Force recommendation statement. Ann Intern Med. 2013; 159(10):698-708.

28. Ziv E, Tice JA, Sprague B, Vachon CM, Cummings SR, Kerlikowske K. Using breast cancer risk associated polymorphisms to identify women for breast cancer chemoprevention. PLoS One. 2017;12(1):e0168601.

29. Keller BM, Chen J, Daye D, Conant EF, Kontos D. Preliminary evaluation of the publicly available Laboratory for Breast Radiodensity Assessment (LIBRA) software tool: comparison of fully automated area and volumetric density measures in a case-control study with digital mammography. Breast Cancer Res. 2015;17:117

30. Ekpo EU, Ujong UP, Mello-Thoms C, McEntee MF. Assessment of interradiologist agreement regarding mammographic breast density classification using the fifth edition of the BI-RADS Atlas. AJR Am J Roentgenol. 2016;206(5):1119-23.

31. Gard CC, Aiello Bowles EJ, Miglioretti DL, Taplin SH, Rutter CM. Misclassification of Breast Imaging Reporting and Data System (BI-RADS) mammographic density and implications for breast density reporting legislation. Breast J. 2015;21(5):481-9.
32. Spayne MC, Gard CC, Skelly J, Miglioretti DL, Vacek PM, Geller BM Reproducibility of BI-RADS breast density measures among community radiologists: a prospective cohort study. Breast J. 2012;18(4):326-33.

33. Gustafson P. Measurement error and misclassification in statistics and epidemiology: impacts and Bayesian adjustments. Boca Raton: Chapman \& Hall/CRC Press; 2004

34. U.S. Food and Drug Administration. MQSA national statistics. https://www.fda. gov/Radiation-EmittingProducts/MammographyQualityStandardsAct andProgram/FacilityScorecard/ucm113858.htm. Accessed 15 Aug 2017.

35. Kerlikowske K, Vachon CM. Breast density: more than meets the eye. J Natl Cancer Inst. 2016;108(10):djw128.

\section{Submit your next manuscript to BioMed Central and we will help you at every step:}

- We accept pre-submission inquiries

- Our selector tool helps you to find the most relevant journal

- We provide round the clock customer support

- Convenient online submission

- Thorough peer review

- Inclusion in PubMed and all major indexing services

- Maximum visibility for your research

Submit your manuscript at www.biomedcentral.com/submit
) Biomed Central 